\title{
Objectively-measured and self-reported physical activity and fitness in relation to inflammatory markers in European adolescents: The HELENA Study
}

David Martinez-Gomez ${ }^{1}$, Sonia Gomez-Martinez ${ }^{1}$, Jonatan R. Ruiz ${ }^{2,3}$, Ligia Esperanza Diaz ${ }^{1}$, Francisco B. Ortega ${ }^{3,4}$, Kurt Widhalm ${ }^{5}$, Magdalena Cuenca-Garcia ${ }^{4}$, Yannis Manios ${ }^{6}$, Tineke De Vriendt ${ }^{7,8}$, Denes Molnar ${ }^{9}$, Inge Huybrechts ${ }^{7}$, Christina Breidenassel ${ }^{10,11}$, Frederic Gottrand $^{12}$, Maria Plada ${ }^{13}$, Sara Moreno ${ }^{11}$, Marika Ferrari ${ }^{14}$, Luis A. Moreno ${ }^{15}$, Michael Sjöström ${ }^{3}$, Ascension Marcos ${ }^{1}$; HELENA Study Group.

${ }^{1}$ Immunonutrition Research Group, Department of Metabolism and Nutrition, Institute of Food Science, Technology and Nutrition (ICTAN), Spanish National Research Council, Madrid. Spain. ${ }^{2}$ Department of Physical Education and Sport, School of Sport Sciences, University of Granada, Granada, Spain. ${ }^{3}$ Unit for Preventive Nutrition, Department of Biosciences and Nutrition at NOVUM, Karolinska Institutet, Huddinge, Sweden. ${ }^{4}$ Department of Medical Physiology, Faculty of Medicine, Granada, Spain. ${ }^{5}$ Division of Nutrition and Metabolism, Department of Pediatrics, Medical University of Vienna, Vienna, Austria. ${ }^{6}$ Department of Nutrition and Dietetics, Harokopio University, Athens, Greece. ${ }^{7}$ Department of Public Health, Faculty of Medicine and Health Sciences, De Pintelaan 185, 2 Blok A, 9000 Ghent, Belgium. ${ }^{8}$ Research Foundation Flanders, Egmontstraat 5, 1000 Brussels, Belgium. ${ }^{9}$ Department of Pediatrics, University of Pecs, Pécs, József A. str. 7, 7623, Hungary.

${ }^{10}$ Department of Nutrition and Food Science, University of Bonn, 53115 Bonn, Germany.

${ }^{11}$ Department of Health and Human Performance. Faculty of Physical Activity and Sport Sciences (INEF). Universidad Politécnica de Madrid, Spain ${ }^{12}$ INSERM U995, IFR114, Faculté de Médecine, Université Droit et Santé de Lille 2, Lille, France. ${ }^{13}$ Department of Social Medicine, School of Medicine, Preventive Medicine and Nutrition Clinic, Crete, Greece. ${ }^{14}$ INRAN (National Research Institute on Food and Nutrition), Via Ardeatina, 546, 00176 Roma, Italy. ${ }^{15}$ GENUD "Growth; Exercise, Nutrition and Development" research group. University School of Health Sciences, University of Zaragoza, Zaragoza, Spain. 
Author for correspondence: David Martinez-Gómez PhD. Immunonutrition Research Group. Department of Metabolism and Nutrition. Instituto de Ciencia y Tecnología de Alimentos y Nutrición. Consejo Superior de Investigaciones Científicas. Calle José Antonio Novais 10, 28040 Madrid, Spain. Phone: +34 915492300 (296/297) Fax: +34 915493627.

Co-ordinator: Luis A. Moreno. 
Core Group members: Luis A. Moreno, Fréderic Gottrand, Stefaan De Henauw, Marcela González-Gross, Chantal Gilbert.

Steering Committee: Anthony Kafatos (President), Luis A. Moreno, Christian Libersa, Stefaan De Henauw, Jackie Sánchez, Fréderic Gottrand, Mathilde Kersting, Michael Sjöstrom, Dénes Molnár, Marcela González-Gross, Jean Dallongeville, Chantal Gilbert, Gunnar Hall, Lea Maes, Luca Scalfi.

Project Manager: Pilar Meléndez.

\section{Universidad de Zaragoza (Spain)}

Luis A. Moreno, Jesús Fleta, José A. Casajús, Gerardo Rodríguez, Concepción Tomás, María I. Mesana, Germán Vicente-Rodríguez, Adoración Villarroya, Carlos M. Gil, Ignacio Ara, Juan Revenga, Carmen Lachen, Juan Fernández Alvira, Gloria Bueno, Aurora Lázaro, Olga Bueno, Juan F. León, Jesús M ${ }^{a}$ Garagorri, Manuel Bueno, Juan Pablo Rey López, Iris Iglesia, Paula Velasco, Silvia Bel.

2. Consejo Superior de Investigaciones Científicas (Spain)

Ascensión Marcos, Julia Wärnberg, Esther Nova, Sonia Gómez, Esperanza Ligia Díaz, Javier Romeo, Ana Veses, Mari Angeles Puertollano, Belén Zapatera, Tamara Pozo, David Martinez-Gomez.

3. Université de Lille 2 (France)

Laurent Beghin, Christian Libersa, Frédéric Gottrand, Catalina Iliescu, Juliana Von Berlepsch.

4. Research Institute of Child Nutrition Dortmund, Rheinische Friedrich-WilhelmsUniversität Bonn (Germany)

Mathilde Kersting, Wolfgang Sichert-Hellert, Ellen Koeppen.

5. Pécsi Tudományegyetem (University of Pécs) (Hungary)

Dénes Molnar, Eva Erhardt, Katalin Csernus, Katalin Török, Szilvia Bokor, Mrs. Angster, Enikö Nagy, Orsolya Kovács, Judit Répasi.

6. University of Crete School of Medicine (Greece)

Anthony Kafatos, Caroline Codrington, María Plada, Angeliki Papadaki, Katerina Sarri, Anna Viskadourou, Christos Hatzis, Michael Kiriakakis, George Tsibinos, Constantine Vardavas Manolis Sbokos, Eva Protoyeraki, Maria Fasoulaki

7. Institut für Ernährungs- und Lebensmittelwissenschaften - Ernährungphysiologie. Rheinische Friedrich Wilhelms Universität (Germany)

Peter Stehle, Klaus Pietrzik, Marcela González-Gross, Christina Breidenassel, Andre Spinneker, Jasmin Al-Tahan, Miriam Segoviano, Anke Berchtold, Christine Bierschbach, Erika Blatzheim, Adelheid Schuch, Petra Pickert.

8. University of Granada (Spain)

Manuel J. Castillo Garzón, Ángel Gutiérrez Sáinz, Francisco B. Ortega Porcel, Jonatan Ruiz Ruiz, Enrique García Artero, Vanesa España Romero, David Jiménez Pavón, Cristóbal Sánchez Muñoz, Victor Soto, Palma Chillón, Jose M. Heredia, Virginia Aparicio, Pedro Baena, Claudia M. Cardia, Ana Carbonell.

9. Istituto Nazionalen di Ricerca per gli Alimenti e la Nutrizione (Italy)

Elena Azzini, Emma Barrison, Noemi Bevilacqua, Pasquale Buonocore, Giovina Catasta, Laura Censi, Donatella Ciarapica, Paola D'Acapito, Marika Ferrari, Myriam Galfo, Cinzia Le Donne, Catherine Leclercq, Giuseppe Maiani, Beatrice Mauro, Lorenza Mistura, Antonella Pasquali, Raffaela Piccinelli, Angela Polito, Raffaella Spada, Stefania Sette, Maria Zaccaria 10. University of Napoli "Federico II" Dept of Food Science (Italy) 
Luca Scalfi, Paola Vitaglione, Concetta Montagnese.

11. Ghent University (Belgium)

Ilse De Bourdeaudhuij, Stefaan De Henauw, Tineke De Vriendt, Lea Maes, Christophe Matthys, Carine Vereecken, Mieke de Maeyer, Charlene Ottevaere, Inge Huybrechts.

12. Medical University of Vienna (Austria)

Kurt Widhalm, Sabine Dietrich.

13. Harokopio University (Greece)

Yannis Manios, Eva Grammatikaki, Zoi Bouloubasi, Tina Louisa Cook, Sofia Eleutheriou, Orsalia Consta, George Moschonis, Ioanna Katsaroli, George Kraniou, Stalo Papoutsou, Despoina Keke, Ioanna Petraki, Elena Bellou, Sofia Tanagra, Kostalenia Kallianoti, Dionysia Argyropoulou, Katerina Kondaki, Stamatoula Tsikrika, Christos Karaiskos.

14. Institut Pasteur de Lille (France)

Jean Dallongeville, Aline Meirhaeghe.

15. Karolinska Institutet (Sweden)

Michael Sjöstrom, Patrick Bergman, María Hagströmer, Lena Hallström, Mårten Hallberg, Eric Poortvliet, Julia Wärnberg, Nico Rizzo, Linda Beckman, Anita Hurtig Wennlöf, Emma Patterson, Lydia Kwak, Lars Cernerud, Per Tillgren, Stefaan Sörensen.

16. Asociación de Investigación de la Industria Agroalimentaria (Spain)

Jackie Sánchez-Molero, Elena Picó, Maite Navarro, Blanca Viadel, José Enrique Carreres, Gema Merino, Rosa Sanjuán, María Lorente, María José Sánchez, Sara Castelló.

17. Campden BRI (United Kingdom)

Chantal Gilbert, Sarah Thomas, Elaine Allchurch, Peter Burguess.

18. SIK - Institutet foer Livsmedel och Bioteknik (Sweden)

Gunnar Hall, Annika Astrom, Anna Sverkén, Agneta Broberg.

19. Meurice Recherche \& Development asbl (Belgium)

Annick Masson, Claire Lehoux, Pascal Brabant, Philippe Pate, Laurence Fontaine.

20. Campden \& Chorleywood Food Development Institute (Hungary)

Andras Sebok, Tunde Kuti, Adrienn Hegyi.

21. Productos Aditivos SA (Spain)

Cristina Maldonado, Ana Llorente.

22. Cárnicas Serrano SL (Spain)

Emilio García.

23. Cederroth International AB (Sweden)

Holger von Fircks, Marianne Lilja Hallberg, Maria Messerer

24. Lantmännen Food R\&D (Sweden)

Mats Larsson, Helena Fredriksson, Viola Adamsson, Ingmar Börjesson.

25. European Food Information Council (Belgium)

Laura Fernández, Laura Smillie, Josephine Wills.

26. Universidad Politécnica de Madrid (Spain)

Marcela González-Gross, Jara Valtueña, David Jiménez-Pavón, Ulrike Albers, Raquel

Pedrero, Agustín Meléndez, Pedro J. Benito, Juan José Gómez Lorente, David Cañada,

Alejandro Urzanqui, Juan Carlos Ortiz, Francisco Fuentes, Rosa María Torres, Paloma

Navarro, Sara Moreno.

\section{INTRODUCTION}

While clinical symptoms are not observed until adulthood, atherosclerotic lesions may form during younger years [1]. There is strong evidence that inflammation plays a key role in 
atherosclerosis development [2]. Atherogenesis involves an inflammatory process that leads to plaque instability within the arterial wall [2]. It also increases blood levels of inflammatory acute-phase reactant proteins (e.g. C-reactive protein [CRP] and complement factors) and cytokines (e.g. interleukin-6 [IL-6] and tumor necrosis factor-alpha [TNF- $\alpha]$ ), which provide useful markers of low-grade inflammation [2].

Several lifestyle-related determinants have been investigated for their antiinflammatory functions during adolescence [3]. Physical activity (PA) and fitness may be important protective factors for low-grade inflammation [3]. However, evidence is scarce and results are mixed regarding the association of PA and fitness with inflammation in adolescents [4]. In addition, previous studies of inflammation in this age group had some critical methodological limitations [4]. Samples were small and homogeneous [4,5] and most investigations used self-reporting to assess PA. The accuracy of self-reporting to measure PA is poor compared with objective means, particularly in younger people $[4,5]$.

Addressing these limitations, the HELENA (HEalthy Lifestyle in Europe by Nutrition in Adolescents) study [6,7] assessed PA and fitness using both objective and self-reporting methods, in a relatively large heterogeneous sample of adolescents from nine European countries, to examine the associations of PA and fitness with inflammatory markers in adolescents.

\section{METHODS}

Design and participants 
The HELENA Cross-Sectional Study (CSS) is a multi-center study aimed at obtaining reliable and comparable data on nutrition and other health indicators such as PA, physical fitness, body composition, cardiovascular disease risk factors, vitamins and mineral status, immunological biomarkers, and genetic markers in European adolescents [6,7]. HELENACSS data collection was undertaken during two school periods between October 2006 and December 2007 in 10 cities from nine European countries: Vienna (Austria), Ghent (Belgium), Lille (France), Dortmund (Germany), Athens and Heraklion (Greece), Pécs (Hungary), Rome (Italy), Zaragoza (Spain), and Stockholm (Sweden). The total sample consisted of 3528 adolescents, of whom 1089 participants gave blood samples. Of the participants with blood parameters, a total of 1041 adolescents had at least one of the inflammatory markers selected in the current study. To minimize the confounder of ongoing infections and chronic inflammatory diseases, 16 adolescents (including 2 girls) with CRP $>10 \mathrm{mg} / 1$ were excluded. After these subjects were excluded, 476 boys and 549 girls $(n=1025)$ participated in this study.

All participants were recruited from schools and met the following criteria established for subjects of the HELENA-CSS [6]: they were (i) aged between 12.5 and 17.5; (ii) free of any acute infection for at least one week prior; (iii) not participating simultaneously in additional clinical trials; and (iv) able to provide information on weight and height. Adolescents and their parents or guardians were provided with information about the HELENA-CSS and all provided a written informed consent. Ethics committees from each country approved the HELENA-CSS protocol and good clinical practices were conducted according to ethical guidelines (8).

\section{Anthropometry}


The anthropometric protocols followed in the HELENA-CSS study are described in detail by Nagy et al. [9]. Briefly, body height was measured to the nearest $0.1 \mathrm{~cm}$ with a stadiometer (SECA 225) while standing barefoot. Body weight was determined to the nearest $100 \mathrm{~g}$ using a balance scale (SECA 861) with subjects in their underwear. Body mass index (BMI) was calculated as body mass ( $\mathrm{kg}$ ) divided by height $(\mathrm{m})$ squared. BMI Z-score was also calculated for each BMI measure with reference to sex- and age-specific limits provided by the International Obesity Task Force (www.iaso.org/iotf/). Waist circumference (WC) was measured in triplicate to the nearest $1 \mathrm{~mm}$ at the midpoint between the superior iliac spine and the costal edge in the midaxillary line, using an anthropometric non-elastic tape (SECA 200).

\section{Assessment of objectively-measured and self-reported PA}

Patterns of PA were objectively assessed using the ActiGraph GT1M (ActiGraphTM, Pensacola, FL, USA), and descriptive data and procedures were detailed in a previous report from the HELENA-CSS [10]. The accelerometer is a small and lightweight uniaxial monitor designed to detect accelerations ranging in magnitude from 0.05 to $2.00 \times \mathrm{g}$ with a frequency response of $0.25-2.50 \mathrm{~Hz}$. The ActiGraph has been widely calibrated for young people in laboratory and free-living conditions. Adolescents wore the accelerometer positioned at the lower back for seven consecutive days. The accelerometer was worn by subjects while awake and only removed during water-based activities. The interval of time called 'epoch' was set at $15 \mathrm{sec}$ according to a consensus of recommendations for assessing PA in youth. Non-wearing time was defined by bouts of at least 20 min of zero outputs. At least three days of valid recording and a minimum of $8 \mathrm{~h} / \mathrm{d}$ were necessary data to be included in the study. The PA variables included in this study were counts per minute (cpm) as a measure of overall PA, and time spent at moderate, vigorous and moderate-to-vigorous PA (MVPA) intensities (min/d). The time spent in moderate and vigorous PA was calculated based upon cutpoints of 2000 and 
$4000 \mathrm{cpm}$ respectively $[11,12]$, whereas the time spent in MVPA was calculated as the combined moderate and vigorous times.

Patterns of PA were also self-reported using the International Physical Activity Questionnaire for Adolescents (IPAQ-A) [13,14]. The IPAQ-A, which is available in several languages (French, Flemish, German, Greek, Hungarian, Italian, Spanish, Swedish and English) covers the following four domains of PA: (i) school-related PA, including activity during physical education and recess; (ii) transportation; (iii) housework; and (iv) extracurricular PA. In each of the domains, the number of days per week and the time periods each day spent walking, in moderate PA and in vigorous PA, were recorded. The data were cleaned and truncated following the guidelines provided by the IPAQ group (www.ipaq.ki.se) $[13,14]$. Consequently, variables obtained by the IPAQ-A for this study were the times spent (min/wk) in moderate PA, vigorous PA, MVPA, and overall PA (MVPA + walking intensities).

\section{Assessment of objectively-measured and self-reported physical fitness}

Physical fitness was assessed using standardized field-based fitness tests for youth [15]. Cardiorespiratory fitness was assessed by the 20-m shuttle-run test. Participants were required to run between two lines $20 \mathrm{~m}$ apart, while keeping pace with audio signals emitted from a pre-recorded CD. The initial speed was $8.5 \mathrm{~km} / \mathrm{h}$, which was increased by $0.5 \mathrm{~km} / \mathrm{h}$ each minute $(1 \min =1$ stage $)$. The test was finished when the participant failed to reach the end lines concurrently with the audio signals on two consecutive occasions. The last stage completed was taken as the participant's CRF. Muscular fitness was assessed using the handgrip strength (maximum handgrip strength, $\mathrm{kg}$ ) and the standing long jump (lower limb explosive strength, $\mathrm{cm}$ ) tests. A single muscular fitness score was computed from the two muscular tests. The individual score of each test was standardized as follows: Z-standardized 
value $=($ value - mean $) / \mathrm{SD}$. The muscular fitness score was calculated as the mean of the two standardized scores. Motor fitness was assessed with the $4 \times 10 \mathrm{~m}$ shuttle-run test of speedof-movement, agility and coordination (measured in seconds). A score of overall fitness was also computed as the average of the three physical fitness components studied after transformation into Z-standardized values. Since the standardized motor fitness score is inversely related to high physical fitness, it was first multiplied by -1 . These physical fitness tests have been shown to be valid and reliable in young people [16].

These three specific fitness components, and overall fitness, were also assessed using four single-response items included in the International FItness Scale (IFIS) [17]. The four 5point Likert-scale items asked the participant to compare their perceived overall fitness, cardiorespiratory fitness, muscular strength and speed/agility (motor fitness) with their friends' physical fitness (very poor, poor, average, good and very good). IFIS was originally written in English and was culturally adapted and translated into all languages involved in the HELENA study. The IFIS scale has shown that (i) it is able to correctly rank adolescents according to their actual physical fitness levels; (ii) adolescents reporting a good/very good overall fitness, cardiorespiratory fitness or speed/agility have a healthier cardiovascular profile; and (iii) IFIS is a reliable method to be used in adolescents [17].

\section{Inflammatory markers}

Blood samples were collected in the early morning after overnight fasting. In all cases, $30 \mathrm{ml}$ of blood was extracted by venipuncture from the antecubital vein by a qualified nurse. The stability of samples during transport and storage in the HELENA study has been reported previously [18]. Five key biomarkers involved in low-grade inflammation were selected for this study [19]. CRP was measured in serum by immunoturbidimetry (AU2700 biochemistry analyzer; Olympus, Watford, UK). C3 and C4 serum complements were analyzed by 
nephelometry (Behring Diagnostics, California, USA). The CVs (inter-assay precision) were $1.9 \%$ for CRP, $1.4 \%$ for C3, and $1.2 \%$ for C4. Serum cytokines IL-6 and TNF- $\alpha$ were determined using the High Sensitivity Human Cytokine MILLIPLEX ${ }^{\mathrm{TM}}$ MAP kit (Millipore Corp., Billerica, MA, USA) and collected by flow cytometry (Luminex-100 v.2.3, Luminex Corporation, Austin, TX, USA. The intra- and inter-assay precision CVs were: $3.5 \%$ and 4.5\% respectively, for IL-6; and 3.5\% and 3.8\%, respectively, for TNF- $\alpha$. Detection limits (sensitivity) for all the analyses were $0.007 \mathrm{mg} / \mathrm{l}$ for CRP, $0.01 \mathrm{~g} / \mathrm{l}$ for C3, $0.002 \mathrm{~g} / \mathrm{l}$ for C4, $0.1 \mathrm{pg} / \mathrm{ml}$ for IL-6, and $0.05 \mathrm{pg} / \mathrm{ml}$ for TNF- $\alpha$. Undetectable values were recorded as the specific detection limit.

\section{Dietary intake}

Total dietary intake data $(\mathrm{kcal} / \mathrm{d})$ and intake $(\mathrm{g} / \mathrm{d})$ of major nutrients (carbohydrates, fat and proteins) were obtained using a dietary assessment tool called HELENA-DIAT, which is based on a self-administered, computerized 24-hr dietary recall named YANA-C (Young Adolescents' Nutrition Assessment on Computer) [20,21]. Two computerized 24-h recalls, were performed, on two non-consecutive days, within two weeks. The YANA-C was completed by the participants in the school's computer room or in a classroom with computers.

\section{Statistical analyses}

Descriptive characteristics are presented as mean (SD) and percentages for continuous and categorical variables, respectively. All variables were checked for normality of distribution before analysis and transformations were performed to achieve normality in the residuals. A natural logarithm transformation was applied to CRP data. Square roots were applied to C3, C4, IL-6 and vigorous PA in both objective and self-reported assessments. 
Differences by sex were determined by analysis of variance (ANOVA). Sex-interactions (sex $\times$ main exposures) were tested to determine whether sex modified the associations of PA or fitness with inflammatory markers. Since no significant interactions were found for sex (all $P>0.2$ ), all analyses were performed with boys and girls together. Partial correlations, controlling for age, sex and city (dummy variable) were used to analyze the relationships between objective and self-reported PA (overall PA, moderate PA, vigorous PA and MVPA), objective and self-reported fitness (overall fitness, cardiorespiratory fitness, muscular fitness and motor fitness) and body fat (BMI and WC). For comparative purposes, partial correlations between inflammatory markers and body fat, controlling for age, sex and city, were calculated (Table 1 supplementary file). Separate models by linear regression analyses were used to determine the associations of objective and self-reported PA and fitness (exposure variables) with inflammatory markers (outcome variables) controlling for age, sex, city (main covariates) and then by body fat (as obesity is considered to be a chronic low-grade inflammatory status [16]) and by dietary intake variables. The associations of PA with lowgrade inflammation markers were additionally controlled for fitness measurements. Analyses were conducted using the software package Predictive Analytics version 18.0 for Macintosh (SPSS Inc., Chicago, IL, USA). The level of significance was set at $P<0.05$ for all analyses. The statistical analyses were adjusted by a weighting factor to balance the sample according to gender and age distribution, and to guarantee true representation of each of the stratified groups.

\section{RESULTS}


The descriptive characteristics of the sample are shown in Table 1. Adolescent boys were taller and heavier than girls and had higher levels of WC. There were no differences between the sexes in CRP, C3 and C4, but adolescent boys had higher levels of IL-6 and TNF- $\alpha$ than girls. In both objective and self-reported measurements, the levels of PA and fitness were significantly greater in boys than girls.

Table 2 shows the partial correlations between PA, fitness and body fat (BMI and WC) using different measurements. Patterns of objectively-measured overall PA, vigorous PA and MVPA were positively correlated with all objective and self-reported indicators of fitness, with the exception of self-reported muscular fitness. Conversely, objectivelymeasured moderate PA was not significantly related to any measures of fitness. Patterns of self-reported PA were also positively correlated with all objective and self-reported indicators, except overall PA and objective muscular fitness. Vigorous PA was negatively correlated with body fat variables, however, other forms of PA were not. On the other hand, objective and self-reported measures of overall fitness, cardiorespiratory fitness and motor fitness were negatively correlated with body fat. Muscular fitness indicators were not related to $\mathrm{WC}$, whereas objective and self-reported muscular fitness were negatively and positively correlated with BMI, respectively. BMI Z-score was significantly associated with all fitness (objective and self-reported) variables (all $P<0.05$ ), but not with any other variables.

Multiple regression analyses with inflammatory markers as dependent variables and objective and self-reported PA and fitness measurements as predictor variables adjusted for age, sex, city and BMI are shown in Table 2 supplementary file and Table 3 . Regarding patterns of PA, only objectively-measured vigorous PA was significantly associated with C3, independent of confounders such as BMI (Table 2 supplementary file). The negative association between vigorous PA and C3 did not remain significant after including any of the objective fitness indicators as a covariate in the model (data not shown). Regarding levels of 
fitness, all the objective measures of fitness were negatively associated with CRP, C3 and C4, independent of the main covariates and BMI (Table 3). Several measures of self-reported fitness were associated with CRP, C3 and C4, but only motor fitness remained significantly associated with $\mathrm{C} 3$ and $\mathrm{C} 4$ independent of BMI. While all significant associations of PA and fitness with CRP, C3 and C4 in model 1 were attenuated when BMI was included in the model, all remained significant. When measured and self-reported fitness were included simultaneously in the model with CRP, C3 and C4 as outcome variables, only objective fitness showed significant associations (data not shown). Levels of IL-6 were not significantly associated with fitness indicators, but motor fitness was negatively associated with TNF- $\alpha$ after controlling for the main covariates and BMI (Table 3). All analyses were repeated using WC and the findings were consistent with those using BMI (Table 3 supplementary file). Finally, when using BMI Z-score instead of BMI and WC, as well as total energy intake or intake of main nutrients as covariates in the models, the principal results did not substantially change (data not shown).

\section{DISCUSSION}


These data, taken from a relatively large and heterogeneous sample of European adolescents, indicate that PA (vigorous) as measured by accelerometry was inversely associated with $\mathrm{C} 3$, irrespective of potential confounders including adiposity indices. However, this association became non-significant after adjusting for fitness measures. Furthermore, objective fitness was inversely associated with three of the five inflammatory markers (CRP, C3 and C4), irrespective of potential confounders and adiposity. Since the interrelationship between PA, fitness and body fat is well-known $[11,12]$, these results suggest that PA has an indirect role in inflammation through fitness and body fat in adolescence. These findings have public health and clinical implications, as adolescence is a period of life characterized by a greater decrease in PA [22, 23]. Also, it becomes important to consider that strategies based on enhancing PA levels in adolescents, to obtain a positive effect on inflammation, may be successful when the intervention improves fitness or body fat outcomes [4]. This may still be the case even though associations to inflammatory markers by enhanced PA levels were not significant.

The associations between PA and inflammatory markers in youth have been mainly examined using self-reported PA and data generated using objective measures is limited [4]. Using both objective and self-reported PA measures of small and homogenous samples has given mixed results with null or inverse associations [4]. Nevertheless, studies using objective measures of PA are in agreement with the current findings. Previously, we examined, for the first time, the associations between objectively-measured PA (accelerometry) and inflammatory markers (CRP, C3, C4 and IL-6) in 192 Spanish adolescents [5]. In this study we found an inversely and marginally significant association between vigorous PA and C3 that disappeared after controlling for potential covariates such as fitness and body fat [5]. Similarly, PA levels measured by accelerometry were not associated with inflammatory markers (CRP, C3, C4 and fibrinogen) in 142 Swedish children [24]. 
The relationship of objective and self-reported measures on the associations between PA and inflammatory factors was low and there were only differences between objective and self-reported vigorous PA in relation to $\mathrm{C} 3$. Nevertheless, other self-reporting tools to assess PA in youth might have a greater influence on these associations. This was shown to be the case by Atienza et al. [25], who examined the associations of self-reported and objectivelymeasured (using accelerometers) MVPA with CRP in a nationally representative sample of US adults from the National Health and Nutritional Examination Survey (NHANES) 20032006. Interestingly, objective and subjective MVPA were independently associated with CRP when both measures were included in the model, but objectively-measured MVPA displayed a stronger association than self-reported MVPA [25]. In addition, Atienza et al. speculated that self-reported PA might serve as a marker for muscular strength as engagement in resistance training activities cannot be accurately captured by accelerometry [25]. Although physical fitness was unfortunately not included as a confounding factor in this study, these results from adults [25] and from adolescents in our current study indicate an age-specific association between PA and inflammation. As inflammatory processes are aggravated with age [2], any type of PA may have a positive impact on lessening inflammation independent of fitness or body fat levels during adulthood. However, improvements of fitness may be important to fight against low-grade inflammation in youth $[3,4]$. For public health and clinical purposes, this age-specific hypothesis must be examined in future longitudinal and intervention studies.

In the current study, we observed that measured overall fitness, as well as three components of fitness (cardiorespiratory, muscular and motor fitness), were modestly related to some inflammatory markers (CRP, C3 and C4), independent of proxy measures of body fat. Our results highlight the 'fat but fit' idea in youth to prevent future cardiovascular diseases [26]. Thus, fitness may have an anti-inflammatory function to counteract obesity- 
induced inflammatory diseases. To our knowledge, no study investigating the influence of overall fitness or motor fitness on low-grade inflammation in adolescents has been undertaken to date. Previous studies that examined the associations between fitness and inflammatory markers also had limitations [4]. Indeed, most studies in youth solely used objective measurements of cardiorespiratory fitness (e.g. sub-maximum cycloergometer and treadmill tests) to examine the associations with low-grade inflammation [4]. These studies had mixed results but, in general, the significant associations were attenuated or non-significant after adjusting for body fat [4]. Regarding muscular fitness, Ruiz et al. [27] found that muscle strength was negatively associated with the inflammatory proteins CRP and prealbumin in overweight adolescents.

Our study used both objective and self-reported measures of fitness in youth. Borodulin et al. [28] found that both self-reported overall physical fitness and measured cardiorespiratory fitness were inversely related to CRP levels, irrespective of body fat, in 3803 Finnish adults. We found that self-reported fitness variables showed significant associations with CRP, C3 and C4 markers, but these relationships were non-significant after body fat and objectively-measured fitness were included in the model. These results suggest that adolescents' self-reported fitness is associated with their measured fitness and body fat levels [17]. On the other hand, the significant associations between self-reported motor fitness and TNF- $\alpha$ remained significant after controlling for the proxy measure of body fat and objectively-measured motor fitness. Although this association cannot be explained in the current study, other factors may mediate the association between self-reported fitness and inflammation. For example, because self-reported fitness is a subjective measure, it might also be influenced by psychological health (e.g. stress, anxiety, well-being, self-esteem and academic performance). In this line, there is certain evidence regarding the influence of stress, cognitive performance and body image on inflammatory activity [29-31]. 
Despite the fact that our study has important strengths, some limitations also deserve attention. Our findings are limited due to its cross-sectional design and causal directionality cannot be inferred. Longitudinal and clinical trials may provide new insights regarding the associations of PA, fitness and body fat with inflammation in youth. Moreover, we obtained blood samples from the participants at only one time point and this might not accurately reproduce a long-term inflammatory status. Finally, more precise measurements of body fat (e.g. magnetic resonance imaging or dual energy X-ray absorptiometry) might be valuable to examine the independent relationships between PA, fitness and low-grade inflammation.

In conclusion, higher PA during adolescence plays an indirect role lessening lowgrade inflammation by enhancing fitness. Fitness and body fat must be considered as important determinants in public health strategies to fight against an inflammatory condition in youth. Longitudinal and intervention studies are warranted.

\section{ACKNOWLEDGEMENTS}

We gratefully acknowledge the help of all participants who took part in the HELENA- 
CSS. The content of this article reflects only the authors' views, and the European

Community is not liable for any use that may be made of the information contained therein.

The HELENA study was supported by the European Community $6^{\text {th }}$ RTD Framework

Programme Contract: FOOD-CT-2005-007034. This study is also being supported by grants from the Spanish Ministry of Education [grant numbers EX-2008-0641, AP2006-02464], the Spanish Ministry of Health (Maternal, Child Health and Development Network, RD08/0072), the Spanish Ministry of Science and Innovation (RYC-2010-05957), the Hungarian Ministry of Health [ETT; grant number 276-06/2009], and the Research Foundation-Flanders [grant number 1.1.746.09.N.01].

CONFLICT OF INTEREST: none declared

\section{AUTHORS' CONTRIBUTION}

a) Substantial contributions to conception and design (KW, YM, DM, FG, LAM, MS and AM), or acquisition of data (SMG, JRR, LED, FBO, MCG, TDV, IH, CB, MP, SM and MF), or analysis and interpretation of data (DMG, JRR and FBO).

b) Drafting the article (DMG, JRR and FBO) or revising it critically for important intellectual content (SGM, LED, KW, MCG, YM, TDV, DM, IH, CB, FG, MP, SM, MF, LAM, MS, and AM)

c) Final approval of the version to be published (all authors).

\section{REFERENCES}


1. Insull W Jr. The pathology of atherosclerosis: plaque development and plaque responses to medical treatment. Am J Med 2009;122:S3-14.

2. Hansson GK. Inflammation, atherosclerosis, and coronary artery disease. N Engl J Med 2005;352:1685-95.

3. Wärnberg J, Nova E, Romeo J, et al. Lifestyle-related determinants of inflammation in adolescence. Br J Nutr 2007;98:S116-20.

4. Thomas NE, Williams DR. Inflammatory factors, physical activity, and physical fitness in young people. Scand J Med Sci Sports 2008;18:543-56.

5. Martinez-Gomez D, Eisenmann JC, Wärnberg J, et al. Associations of physical activity, cardiorespiratory fitness and fatness with low-grade inflammation in adolescents: the AFINOS Study. Int J Obes (Lond) 2010;34:1501-7.

6. Moreno LA, González-Gross M, Kersting M, et al. Assessing, understanding and modifying nutritional status, eating habits and physical activity in European adolescents: the HELENA (Healthy Lifestyle in Europe by Nutrition in Adolescence) Study. Public Health Nutr 2008;11:288-99.

7. Moreno LA, De Henauw S, González-Gross M, et al. Design and implementation of the Healthy Lifestyle in Europe by Nutrition in Adolescence Cross-Sectional Study. Int J Obes (Lond) 2008;32:4S-11S.

8. Béghin L, Castera M, Manios Y, et al. Quality assurance of ethical issues and regulatory aspects relating to good clinical practices in the HELENA Cross-Sectional Study. Int $\mathbf{J}$ Obes (Lond) 2008;32:S12-8.

9. Nagy E, Vicente-Rodriguez G, Manios Y, et al. Harmonization process and reliability assessment of anthropometric measurements in a multicenter study in adolescents. Int $\mathbf{J}$ Obes (Lond) 2008;32:S58-65. 
10. Ruiz JR, Ortega FB, Martínez-Gómez D, et al. Objectively Measured Physical Activity and Sedentary Time in European Adolescents: The HELENA Study. Am J Epidemiol 2011.

11. Martinez-Gomez D, Ruiz JR, Ortega FB, et al. Recommended levels and intensities of physical activity to avoid low-cardiorespiratory fitness in European adolescents: The HELENA study. Am J Hum Biol. 2010 Nov-Dec;22(6):750-6.

12. Martinez-Gomez D, Ruiz JR, Ortega FB, et al. Recommended levels of physical activity to avoid an excess of body fat in European adolescents: the HELENA Study. Am J Prev Med. 2010 Sep;39(3):203-11.

13. De Cocker K, Ottevaere C, Sjöström M, et al. Self-reported physical activity in European adolescents: results from the HELENA (Healthy Lifestyle in Europe by Nutrition in Adolescence) study. Public Health Nutr 2011;14:246-54.

14. Hagströmer M, Bergman P, De Bourdeaudhuij I, et al. Concurrent validity of a modified version of the International Physical Activity Questionnaire (IPAQ-A) in European adolescents: The HELENA Study. Int J Obes (Lond) 2008;32:S42-8.

15. Ortega FB, Artero EG, Ruiz JR, et al. Physical fitness levels among European adolescents: the HELENA study. Br J Sports Med 2011;45:20-9.

16. Ruiz JR, Castro-Piñero J, España-Romero V, et al. Field-based fitness assessment in young people: the ALPHA health-related fitness test battery for children and adolescents. Br J Sports Med 2011;45:518-24.

17. Ortega FB, Ruiz JR, España-Romero V, et al. The International Fitness Scale (IFIS): usefulness of self-reported fitness in youth. Int J Epidemiol 2011.

18. González-Gross M, Breidenassel C, Gómez-Martínez S, et al. Sampling and processing of fresh blood samples within a European multicenter nutritional study: evaluation of biomarker stability during transport and storage. Int J Obes (Lond) 2008;32:S66-75. 
19. Wärnberg J, Nova E, Moreno LA, et al. Inflammatory proteins are related to total and abdominal adiposity in a healthy adolescent population: the AVENA Study. Am J Clin Nutr 2006;84:505-12.

20. Vereecken C, De Henauw S, Maes L, et al. Reliability and validity of a healthy diet determinants questionnaire for adolescents. Public Health Nutr. 2009;12:1830-8.

21. Vereecken CA, Covents M, Sichert-Hellert W, et al. Development and evaluation of a self-administered computerized 24-h dietary recall method for adolescents in Europe. Int J Obes (Lond). 2008;32:S26-34.

22. Malina RM. Tracking of physical activity and physical fitness across the lifespan. Res Q Exerc Sport 1996;67:S48-57.

23. Nader PR, Bradley RH, Houts RM, McRitchie SL, O'Brien M. Moderate-to-vigorous physical activity from ages 9 to 15 years. JAMA 2008;300:295-305.

24. Ruiz JR, Ortega FB, Warnberg J, Sjöström M. Associations of low-grade inflammation with physical activity, fitness and fatness in prepubertal children; the European Youth Heart Study. Int J Obes (Lond) 2007;31:1545-51.

25. Atienza AA, Moser RP, Perna F, et al. Self-Reported and Objectively-Measured Activity Related To Biomarkers Using NHANES. Med Sci Sports Exerc 2011;43:815-21.

26. Eisenmann JC. Aerobic fitness, fatness and the metabolic syndrome in children and adolescents. Acta Paediatr 2007;96:1723-9.

27. Ruiz JR, Ortega FB, Wärnberg J, et al. Inflammatory proteins and muscle strength in adolescents: the Avena study. Arch Pediatr Adolesc Med 2008;162:462-8.

28. Borodulin K, Laatikainen T, Salomaa V, Jousilahti P. Associations of leisure time physical activity, self-rated physical fitness, and estimated aerobic fitness with serum Creactive protein among 3,803 adults. Atherosclerosis 2006;185:381-7. 
29. Wärnberg J, Gomez-Martinez S, Romeo J, Díaz LE, Marcos A. Nutrition, inflammation, and cognitive function. Ann N Y Acad Sci 2009;1153:164-75.

30. Fuligni AJ, Telzer EH, Bower J, et al. A preliminary study of daily interpersonal stress and C-reactive protein levels among adolescents from Latin American and European backgrounds. Psychosom Med 2009;71:329-33.

31. Sabiston C, Castonguay A, Barnett T, O'Loughlin J, Lambert M. Body image and Creactive protein in adolescents. Int J Obes (Lond) 2009;33:597-600. 
Table 1. Physical characteristics of the study sample

\begin{tabular}{|c|c|c|c|c|c|c|}
\hline & $N$ & All & $n$ & Boys & $n$ & Girls \\
\hline Age, yr & 1025 & $14.8(1.2)$ & 476 & $14.8(1.2)$ & 549 & $14.7(1.2)$ \\
\hline Weight, $\mathrm{kg}$ & 1025 & $58.6(12.5)$ & 476 & $61.9(14.2)$ & 549 & $55.7(10.0)^{*}$ \\
\hline Height, $\mathrm{m}$ & 1025 & $165.5(9.3)$ & 476 & $169.7(10.0)$ & 549 & $161.8(7.0)^{*}$ \\
\hline Body mass index, $\mathrm{kg} / \mathrm{m}^{2}$ & 1025 & $21.3(3.6)$ & 476 & $21.4(3.9)$ & 549 & $21.2(3.3)$ \\
\hline Body mass index, Z-score & 1025 & $0.5(1.1)$ & 476 & $0.6(1.2)$ & 549 & $0.4(1.1)^{*}$ \\
\hline Waist circumference, $\mathrm{cm}$ & 1010 & $72.4(8.7)$ & 467 & $74.5(9.2)$ & 543 & $70.6(7.8)^{*}$ \\
\hline Total energy intake, $\mathrm{kcal} / \mathrm{d}$ & 670 & 2276 (1036) & 312 & $2675(1155)$ & 357 & $1926(767)^{*}$ \\
\hline Total carbohydrates intake, g/d & 670 & $276(131)$ & 312 & $323(151)$ & 357 & $234(92)^{*}$ \\
\hline Total fat intake, $\mathrm{g} / \mathrm{d}$ & 670 & $91(51)$ & 312 & $107(57)$ & 357 & $77(40)^{*}$ \\
\hline Total protein intake, g/d & 670 & $87(42)$ & 312 & $103(45)$ & 357 & $73(34) *$ \\
\hline European cities, $\%$ of total sample & 1025 & & 476 & & 549 & \\
\hline Athens, Greece & & 7.4 & & 6.7 & & 8.0 \\
\hline Dortmund, Germany & & 11.4 & & 13.9 & & 9.3 \\
\hline Gent, Belgium & & 10.5 & & 11.6 & & 9.7 \\
\hline Heraklion, Greece & & 9.2 & & 9.7 & & 8.7 \\
\hline Lille, France & & 8.4 & & 7.6 & & 9.1 \\
\hline Pecs, Hungary & & 13.0 & & 10.9 & & 14.8 \\
\hline Roma, Italy & & 9.6 & & 10.1 & & 9.1 \\
\hline Stockholm, Sweden & & 9.7 & & 10.3 & & 9.1 \\
\hline Vienna, Austria & & 10.8 & & 9.9 & & 11.7 \\
\hline Zaragoza, Spain & & 10.0 & & 9.5 & & 10.6 \\
\hline \multicolumn{7}{|l|}{ Inflammatory markers } \\
\hline $\mathrm{CRP}, \mathrm{mg} / \mathrm{l}^{\mathrm{a}}$ & 997 & $0.8(1.2)$ & 461 & $0.9(1.2)$ & 536 & $0.8(1.2)$ \\
\hline $\mathrm{C} 3, \mathrm{~g} / \mathrm{l}^{\mathrm{b}}$ & 997 & $1.1(0.2)$ & 461 & $1.1(0.2)$ & 536 & $1.1(0.2)$ \\
\hline $\mathrm{C} 4, \mathrm{~g} / 1^{\mathrm{b}}$ & 988 & $0.2(0.1)$ & 458 & $0.2(0.1)$ & 530 & $0.2(0.1)$ \\
\hline IL-6, $\mathrm{pg} / \mathrm{ml}^{\mathrm{b}}$ & 962 & $22.4(33.2)$ & 452 & $27.0(40.5)$ & 510 & $18.3(24.5)^{*}$ \\
\hline TNF- $\alpha, p g / \mathrm{ml}^{\mathrm{b}}$ & 962 & $6.7(11.2)$ & 453 & $7.9(15.8)$ & 509 & $5.5(3.4)^{*}$ \\
\hline \multicolumn{7}{|c|}{ Objectively measured PA (Accelerometry) } \\
\hline Overall PA, cpm & 682 & 440 (157) & 301 & $506(170)$ & 381 & $388(124)^{*}$ \\
\hline Moderate PA, $\mathrm{min} / \mathrm{d}$ & 682 & $41(15)$ & 301 & $45(16)$ & 381 & $38(13)^{*}$ \\
\hline Vigorous PA, $\mathrm{min} / \mathrm{d}^{\mathrm{b}}$ & 682 & $19(14)$ & 301 & $25(16)$ & 381 & $14(11)^{*}$ \\
\hline MVPA, $\min / \mathrm{d}$ & 682 & $60(25)$ & 301 & $70(26)$ & 381 & $52(21)^{*}$ \\
\hline \multicolumn{7}{|l|}{ Self-reported PA (IPAQ-A) } \\
\hline Overall PA, min/wk & 865 & $1155(834)$ & 391 & $1282(878)$ & 474 & $1050(783)^{*}$ \\
\hline Moderate PA, $\min / w k$ & 865 & 487 (391) & 391 & $532(407)$ & 474 & $449(375)^{*}$ \\
\hline Vigorous PA, $\mathrm{min} / \mathrm{wk}^{\mathrm{b}}$ & 865 & $239(303)$ & 391 & $328(331)$ & 474 & $165(255)^{*}$ \\
\hline MVPA, min/wk & 865 & $726(600)$ & 391 & $860(644)$ & 474 & $614(538)^{*}$ \\
\hline \multicolumn{7}{|c|}{ Objectively measured fitness (HELENA tests) } \\
\hline Overall fitness, Z-score & 755 & $0(0.8)$ & 362 & $0.6(0.7)$ & 393 & $-0.5(0.6) *$ \\
\hline Cardiorespiratory fitness, stage & 779 & $5(3)$ & 373 & $6(3)$ & 406 & $3(2)^{*}$ \\
\hline Muscular fitness, Z-score & 941 & $0(0.9)$ & 432 & $0.6(0.9)$ & 509 & $-0.5(0.5)^{*}$ \\
\hline Motor fitness, sec & 920 & $12.2(1.3)$ & 428 & $11.5(1.1)$ & 492 & $12.8(1.2)^{*}$ \\
\hline \multicolumn{7}{|l|}{ Self-reported fitness (IFIS scale) ${ }^{c}$} \\
\hline Overall fitness, score & 957 & $3.7(0.9)$ & 445 & $4.0(0.9)$ & 512 & $3.5(0.9)^{*}$ \\
\hline Cardiorespiratory fitness, score & 955 & $3.5(0.9)$ & 443 & $3.8(0.9)$ & 512 & $3.3(0.9)^{*}$ \\
\hline Muscular fitness, score & 957 & $3.5(0.9)$ & 445 & $3.8(0.8)$ & 512 & $3.3(0.8)^{*}$ \\
\hline Motor fitness, score & 956 & $3.7(0.9)$ & 445 & $3.9(0.9)$ & 511 & $3.5(0.9)^{*}$ \\
\hline \multicolumn{7}{|c|}{$\begin{array}{l}\text { Values are mean (SD) or \%. CRP: C-reactive protein. C3: complement factor. C4: complement factor C4. IL-6: Interleukin- } 6 . \\
\text { TNF- } \alpha \text { : tumor necrosis factor- } \alpha \text {. PA: physical Activity. MVPA: moderate-to-vigorous PA. IPAQ-A: International PA } \\
\text { Questionnaire for Adolescents. IFIS: International Fitness Scale. }{ }^{\mathrm{a}} \text { Values were natural log-transformed before analysis, but non- } \\
\text { transformed values are presented in the table. }{ }^{b} \text { Values were square root transformed before analysis, but non-transformed values } \\
\text { are presented in the table. }{ }^{\mathrm{c}} \text { Likert scales ranging from } 1 \text { to } 5 .{ }^{*} P<0.05 \text { denotes statistical significance between genders. }\end{array}$} \\
\hline
\end{tabular}


Table 2. Partial correlations between physical activity (PA), fitness and fatness in European adolescents ( $n=1025)$

\begin{tabular}{|c|c|c|c|c|c|c|c|c|c|c|}
\hline & \multicolumn{2}{|c|}{ Overall PA } & \multicolumn{2}{|c|}{ Moderate PA } & \multicolumn{2}{|c|}{ Vigorous PA $^{\mathrm{d}}$} & \multicolumn{2}{|c|}{ MVPA } & \multicolumn{2}{|c|}{ Fatness } \\
\hline & $\begin{array}{l}\text { Objective } \\
\text { (cpm) }\end{array}$ & $\begin{array}{l}\text { Self-reported } \\
(\mathrm{min} / \mathrm{wk})\end{array}$ & $\begin{array}{l}\text { Objective } \\
\text { (min/d) }\end{array}$ & $\begin{array}{c}\text { Self-reported } \\
(\mathrm{min} / \mathrm{wk})\end{array}$ & $\begin{array}{c}\text { Objective } \\
(\mathrm{min} / \mathrm{d})\end{array}$ & $\begin{array}{l}\text { Self-reported } \\
(\mathrm{min} / \mathrm{wk})\end{array}$ & $\begin{array}{l}\text { Objective } \\
\text { (min/d) }\end{array}$ & $\begin{array}{l}\text { Self-reported } \\
(\mathrm{min} / \mathrm{wk})\end{array}$ & $\begin{array}{c}\mathrm{BMI} \\
\left(\mathrm{kg} / \mathrm{m}^{2}\right)\end{array}$ & $\begin{array}{c}\mathrm{WC} \\
(\mathrm{cm})\end{array}$ \\
\hline \multicolumn{11}{|l|}{ Overall fitness } \\
\hline Objective (Z-score $)^{\mathrm{a}}$ & $0.162 * * *$ & $0.102 * *$ & 0.035 & $0.139 * * *$ & $0.221 * * *$ & $0.219 * * *$ & $0.148 * * *$ & $0.202 * * *$ & $-0.362 * * *$ & $-0.322 * * *$ \\
\hline Self-reported (score) ${ }^{b}$ & $0.131 * * *$ & $0.201 * * *$ & 0.058 & $0.157 * * *$ & $0.162 * * *$ & $0.238 * * *$ & $0.128 * * *$ & $0.223 * * *$ & $-0.178 * * *$ & $-0.202 * * *$ \\
\hline \multicolumn{11}{|l|}{ Cardiorespiratory fitness } \\
\hline Objective (stage) & $0.129^{* *}$ & $0.082 *$ & 0.038 & $0.143 * * *$ & $0.174 * * *$ & $0.183 * * *$ & $0.123^{* *}$ & $0.188 * * *$ & $-0.385 * * *$ & $-0.337 * * *$ \\
\hline Self-reported (score) ${ }^{b}$ & $0.110^{* *}$ & $0.182 * * *$ & 0.043 & $0.140 * * *$ & $0.144 * * *$ & $0.202 * * *$ & $0.108^{* *}$ & $0.194 * * *$ & $-0.161 * * *$ & $-0.177 * * *$ \\
\hline \multicolumn{11}{|l|}{ Muscular fitness } \\
\hline Objective (Z-score) ${ }^{\mathrm{c}}$ & $0.103^{* *}$ & $0.112 * * *$ & -0.029 & $0.101^{* *}$ & $0.171 * * *$ & $0.178 * * *$ & $0.080 *$ & $0.156^{* * *}$ & $-0.073^{*}$ & -0.056 \\
\hline Self-reported (score) ${ }^{b}$ & 0.066 & $0.141 * * *$ & 0.015 & $0.100^{* *}$ & 0.074 & $0.150 * * *$ & 0.051 & $0.141 * * *$ & $0.093 * *$ & 0.045 \\
\hline \multicolumn{11}{|l|}{ Motor fitness } \\
\hline Objective $(\sec \times-1)$ & $0.133 * * *$ & 0.048 & 0.049 & $0.078^{*}$ & $0.166^{* * *}$ & $0.162 * * *$ & $0.125 * * *$ & $0.133 * * *$ & $-0.336^{* * *}$ & $-0.301 * * *$ \\
\hline Self-reported (score) ${ }^{b}$ & $0.078^{*}$ & $0.165^{* * *}$ & 0.037 & $0.107^{* *}$ & $0.107 * *$ & $0.155^{* * *}$ & $0.084 *$ & $0.148 * * *$ & $-0.232 * * *$ & $-0.238 * * *$ \\
\hline \multicolumn{11}{|l|}{ Fatness } \\
\hline Body mass index $\left(\mathrm{kg} / \mathrm{m}^{2}\right)$ & -0.016 & 0.027 & 0.033 & -0.028 & $-0.088^{*}$ & 0.015 & -0.030 & -0.011 & - & $0.883 * * *$ \\
\hline Waist circumference $(\mathrm{cm})$ & -0.028 & -0.014 & 0.017 & -0.043 & $-0.085^{*}$ & -0.006 & -0.038 & -0.032 & - & - \\
\hline
\end{tabular}

Analyses were adjusted for age, sex and city. MVPA: moderate-to-vigorous PA. ${ }^{a}$ Z-score computed from 20 -m shuttle-run, handgrip strength, standing broad jump, and $4 \times 10-\mathrm{m}$ shuttle-run tests. ${ }^{\mathrm{b}}$ Likert scales ranging from 1 to $5 .{ }^{\mathrm{c}} \mathrm{Z}$-score computed from handgrip strength and standing broad jump tests.

${ }^{\mathrm{d}}$ Values were square root transformed before analysis. ${ }^{*} P<0.05, * * P<0.01, * * * P<0.001$ denotes statistical significance. 
Table 3. Associations of objectively measured and self-reported fitness with inflammatory markers in European adolescents $(n=1025)$

\begin{tabular}{|c|c|c|c|c|c|c|c|c|c|c|c|c|c|c|c|c|}
\hline & \multicolumn{4}{|c|}{ Overall fitness } & \multicolumn{4}{|c|}{ Cardiorespiratory fitness } & \multicolumn{4}{|c|}{ Muscular fitness } & \multicolumn{4}{|c|}{ Motor fitness } \\
\hline & \multicolumn{2}{|c|}{ 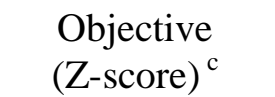 } & \multicolumn{2}{|c|}{$\begin{array}{l}\text { Self-reported } \\
\quad(\text { score })^{d}\end{array}$} & \multicolumn{2}{|c|}{$\begin{array}{l}\text { Objective } \\
\text { (stage) }\end{array}$} & \multicolumn{2}{|c|}{$\begin{array}{l}\text { Self-reported } \\
\quad(\text { score })^{d}\end{array}$} & \multicolumn{2}{|c|}{ 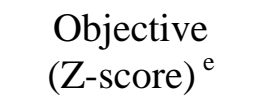 } & \multicolumn{2}{|c|}{$\begin{array}{l}\text { Self-reported } \\
{\text { (score })^{\mathrm{d}}}^{\text {s. }}\end{array}$} & \multicolumn{2}{|c|}{$\begin{array}{l}\text { Objective } \\
(\sec \times-1)\end{array}$} & \multicolumn{2}{|c|}{$\begin{array}{l}\text { Self-reported } \\
(\text { score })^{d}\end{array}$} \\
\hline & $\beta$ & $P$ & ß & $P$ & ß & $P$ & $\beta$ & $P$ & $\beta$ & $P$ & ß & $P$ & $\beta$ & $P$ & $\beta$ & $P$ \\
\hline \multicolumn{17}{|l|}{ Model 1} \\
\hline $\mathrm{CRP}(\mathrm{mg} / \mathrm{l})^{\mathrm{a}}$ & -0.218 & $<0.001$ & -0.038 & 0.269 & -0.188 & $<0.001$ & -0.062 & 0.072 & -0.180 & $<0.001$ & -0.007 & 0.842 & -0.150 & $<0.001$ & -0.099 & 0.003 \\
\hline $\mathrm{C} 3(\mathrm{~g} / \mathrm{l})^{\mathrm{b}}$ & -0.346 & $<0.001$ & -0.117 & 0.001 & -0.259 & $<0.001$ & -0.093 & 0.006 & -0.255 & $<0.001$ & 0.001 & 0.980 & -0.236 & $<0.001$ & -0.148 & $<0.001$ \\
\hline $\mathrm{C} 4(\mathrm{~g} / \mathrm{l})^{\mathrm{b}}$ & -0.286 & $<0.001$ & -0.088 & 0.009 & -0.216 & $<0.001$ & -0.069 & 0.043 & -0.177 & $<0.001$ & -0.020 & 0.543 & -0.225 & $<0.001$ & -0.135 & $<0.001$ \\
\hline IL-6 (pg/ml) ${ }^{b}$ & -0.016 & 0.765 & -0.024 & 0.480 & 0.025 & 0.617 & -0.054 & 0.122 & -0.028 & 0.556 & -0.010 & 0.765 & -0.046 & 0.264 & -0.013 & 0.705 \\
\hline TNF- $\alpha(\mathrm{pg} / \mathrm{ml})$ & -0.023 & 0.654 & -0.041 & 0.235 & -0.020 & 0.680 & -0.012 & 0.733 & -0.037 & 0.436 & -0.036 & 0.386 & -0.038 & 0.360 & -0.070 & 0.036 \\
\hline \multicolumn{17}{|l|}{ Model 1 + BMI } \\
\hline $\mathrm{CRP}(\mathrm{mg} / \mathrm{l})^{\mathrm{a}}$ & -0.152 & 0.004 & 0.004 & 0.918 & -0.124 & 0.011 & -0.023 & 0.502 & -0.134 & 0.004 & -0.019 & 0.576 & -0.088 & 0.034 & -0.053 & 0.120 \\
\hline $\mathrm{C} 3(\mathrm{~g} / \mathrm{l})^{\mathrm{b}}$ & -0.232 & $<0.001$ & -0.055 & 0.091 & -0.145 & 0.002 & -0.032 & 0.330 & -0.179 & $<0.001$ & -0.017 & 0.596 & -0.140 & $<0.001$ & -0.075 & 0.022 \\
\hline $\mathrm{C} 4(\mathrm{~g} / \mathrm{l})^{\mathrm{b}}$ & -0.209 & $<0.001$ & -0.041 & 0.225 & -0.140 & 0.003 & -0.024 & 0.482 & -0.120 & 0.008 & -0.036 & 0.276 & -0.154 & $<0.001$ & -0.082 & 0.014 \\
\hline IL-6 (pg/ml) ${ }^{\mathrm{b}}$ & -0.007 & 0.902 & -0.022 & 0.528 & 0.032 & 0.524 & -0.053 & 0.139 & -0.024 & 0.614 & -0.011 & 0.745 & -0.043 & 0.323 & -0.010 & 0.781 \\
\hline $\mathrm{TNF}-\alpha(\mathrm{pg} / \mathrm{ml})$ & -0.030 & 0.591 & -0.039 & 0.264 & -0.025 & 0.627 & -0.009 & 0.790 & -0.036 & 0.488 & -0.037 & 0.273 & -0.045 & 0.302 & -0.071 & 0.041 \\
\hline
\end{tabular}

B: standardized coefficients. Model 1: adjusted for age, sex and city. CRP: C-reactive protein. C3: complement factor. C4: complement factor C4. IL-6: Interleukin-6. TNF- $\alpha$ : tumor necrosis factor- $\alpha$. BMI: body mass index. ${ }^{\mathrm{a}}$ Values were natural log-transformed before analysis. ${ }^{\mathrm{b}}$ Values were square root transformed before analysis. ${ }^{\mathrm{c}}$ Z-score computed from 20 -m shuttle-run, handgrip strength, standing broad jump, and 4x10-m shuttle-run tests. ${ }^{\mathrm{d}}$ Likert scales ranging from 1 to $5 .{ }^{\mathrm{e}} \mathrm{Z}$-score computed from handgrip strength, and standing broad jump tests. 